\title{
Computer Based Technologies in Marine Sciences
}

\author{
${ }^{1}$ Eljona, Zanaj, ${ }^{2}$ Eva Cipi \\ Department of Computer Science \\ "Ismail Qemali" University \\ Vlora, Albania \\ 1eljona@live.co.uk; ${ }^{2}$ eva.cipi@yahoo.com
}

\author{
Ina Nasto \\ Department of Biology \\ "Ismail Qemali" University \\ Vlora, Albania \\ ina.nasto@yahoo.com
}

\begin{abstract}
In the last years, there has been an advancement in technology, thus, new tools have become available for the study of marine sciences. Scientists and engineers have worked together to give a plethora of tools to help in marine sciences, either environment monitoring, statistical data or numeric models. We use different tools in marine sciences, such as ArcGIS for display and manipulation of geospatial data, $R$ for statistical analysis, SPSS for statistical data. The addressed question is which one of these tools is the most suitable for use. This paper explores the most commonly used tools, the advantages and drawbacks of using them as well as their prospective challenges.
\end{abstract}

Keywords; Marine sciences; technology; simulation programs

\section{INTRODUCTION}

The evolvement of new tools for the study of marine sciences has become an integral part of the research in new technologies. When deciding what technology is best suited in studying an environment, it is first essential to determine what study we would like to conduct: on one hand observing oceans or lagoons, on the other hand examining the population of a habitat or the weather conditions. There are so many parameters that we need to take into consideration.

\section{TECHNOLOGIES}

With the help of new alternative methods alongside with the help of technology, the researchers were able to solve some of the problems such as the difficulty of working at sea for an everlasting period, the hydrostatic pressure, the preservation of the fauna without conducting invasive research, etc.

\section{A. Monitoring the oceans}

Over the past 10 years, there has been a tremendous improvement in our capacity to measure ocean currents on both spatial and temporal scales. One technology which is greatly used is remote sensing, using satellites to measure characteristics of the ocean, such as: color, temperature, surface elevation and the overlaying atmosphere [1, 2, 3]. With the help of these observations, we can map the physical forces that drive ocean circulation. A new land-based remote sensing technique that has established an ample use is the Coastal Ocean Dynamics Application Radar, which makes it possible to measure the movements of surface currents within a few kilometers of the shore. Monitoring the oceans is an important part because it helps us track the changes that occur, either seasonal changes or more permanent ones.
The biggest advancements in using remote sensing is the survey of coral reefs, mangroves [4], kelp, algal beds and estuaries $[5,6]$. Ocean circulation has a profound impact on coastal ecosystems; therefore, it is very important to be able to know what drives it. In order to pursue this step, in his study of marine larvae, James et al. [7] used numerical models to simulate ocean currents around individual reefs in the Great Barrier Reef. The amelioration of remote sensing, combined with moored instruments, great insight shave shed light into the ocean circulation, especially in the Point Conception on the Californian coast $[8,9]$.

Over the last decade, aerospace technology has helped in solving many problems with real-time monitoring of seas and oceans. Owing to modern advanced satellite instruments, multi-parameter probes and environmental monitoring sensors, it has been possible to collect a wide range of significant water environment parameters:

- the changes of bio-optical parameters, such as water color, turbidity, phytoplankton, Fig. 1, concentration and liquid or solid suspended substances $[10,11,12]$.

- the observations of hydrodynamic parameters such as the reduction of sea currents, turbulence and direction of waves $[13,14]$.

- the fluctuations of the surface temperature of seas and oceans and other physical, chemical parameters such as salinity, concentration of heavy metals, etc. $[15,16]$.

- the changes in biological parameters such as nitrates and phosphates, and water $\mathrm{pH}[17,18]$.

- the variations in the ocean level caused by tidal and reflux phenomena, geostrophic currents, tsunami waves, etc.;

- the changes of sea level caused by global warming, marine erosion [19].

Fig. 1 shows an open access site which uses NASA's satellites to measure light diffraction and water coloration.

Measurement of phytoplankton concentration is an important finding for assessing primary ocean production.

To be able to quantitatively, mechanically estimate the constituent concentrations, models developed are able to link ocean color with desired components. In ocean color remote 
sensing, "ocean color" is commonly described with the spectrum of remote sensing reflectance, which is defined as the ratio of water-leaving radiance to downside irradiance just above the surface [20]. "Water-leaving radiance" represents photons from absorption and scattering processes, from the surface to emitting space, two-sea-surface-reflectance, a process of having no information in-water constituents.

Variation of color depends on phytoplankton physiology, species composition and phytoplankton day-night migration. Its value cannot be directly provided by ocean color remote sensing, but it has been estimated and modeled based on laboratory and / or field measurements [20].

Thanks to this standardized method and space technology, it is possible for researchers to access the same data, with a minimum margin of error.

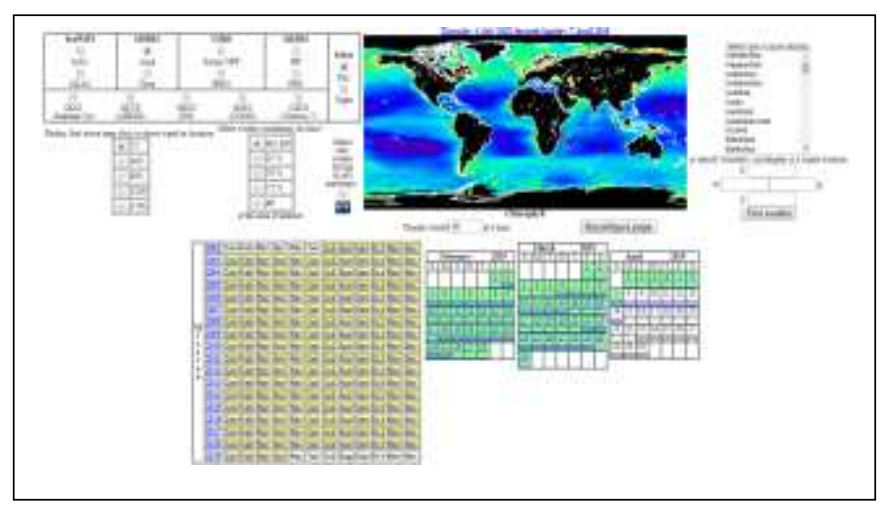

Figure 1. Phytoplankton satellite monitoring. http://oceancolor.gsfc.nasa.gov

\section{B. Mapping of sea bottom topography}

A wide range of seabed-mapping technologies is reviewed in respect to their effectiveness in discriminating benthic habitats at different spatial scales. Of the seabed attributes considered important in controlling the benthic community of marine sands and gravel, sediment grain size, porosity or shear strength, and sediment dynamics were highlighted as the most important. Whilst no mapping system can quantify all these attributes at the same time, some may be estimated by skillful interpretation of the remotely sensed data. For example, seabed processes or features, such as bed form migration, scour, slope failure, and gas venting are readily detectable by many of the mapping systems, and these characteristics in turn can be used to assist a habitat classification (and monitoring) of the seabed [21].

The most commonly versatile used systems are SSS and multi-beam swath bathymetric devices, Figure 2 (here called multi-beam echo-sounders, MBES). These systems are subsequently described in more detail in a tabulated comparison with other devices, such as ground-discriminating single-beam echo-sounders (acoustic ground discrimination systems, AGDS), highlighting their advantages and disadvantages for various seabed-mapping applications.

A major advantage is that under optimal conditions, SSS can generate an almost photo-realistic picture of the seabed. Once several swaths have been mosaicked, geological and sediment logical features are easily recognizable, and their interpretation provides a valuable qualitative insight into the dynamics of the seabed. However, the quality (or amplitude) of the data varies. For example, the grey-scale (signal amplitude) between swaths covering the same area of the seabed differs often noticeably.

According to [22], a sonar processor accepts acoustic signals (sound waves) detected by a sensor array in the ocean, extracts the characteristics of those signals, and presents the characteristics on a visual display. Typically, sensor arrays processed in SSs are from 10 to $1000 \mathrm{ft}$. in length and contain 50 to 1000 sensors or hydrophones. The signals received on such arrays must be characterized both by direction of arrival, called spatial processing or beamforming, and by time evolution, called spectral processing. Generally, the spatial and spectral processing can be performed separately with no loss in the detectability of the signals. From this description, one can view a passive sonar processor as a combination of a beam former, a spectrum analyzer, and a display. As Fig. 3 indicates, sensors are sometimes recorded on magnetic or other media rather than being processed directly. Most of the processors developed by SSs have been designed as shore-based systems for sensor data recorded on magnetic media during operational submarine missions. The output of the spectrum analyzer is stored on magnetic disk prior to display and analysis. Use of such intermediate storage allows the analysis of the data to proceed on a different schedule from the processing. Since the various sonar processors may execute at different rates, the individual processors must also have access to memory buffers to smooth the flow of results among units. A distributed architecture naturally provides modularity, which eases system integration and allows new processors to be added as needed. Finally, any architecture must support the programmability of algorithms and algorithm parameters.

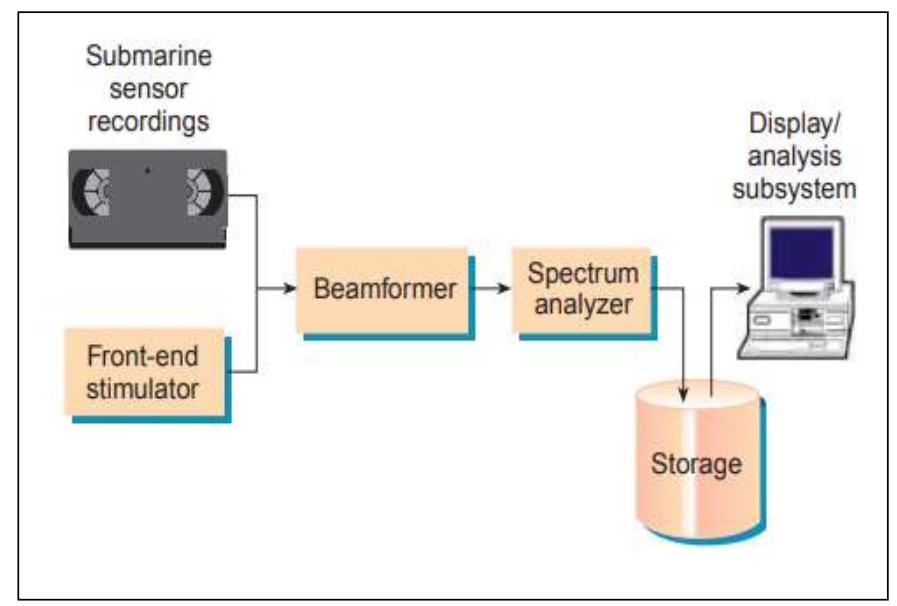

Figure 2. Functional components of passive sonars [22].

According to [23], the processed sonar imagery is composed of elements (pixels) organized into one or several images. These pixels are located by relative coordinates, usually respective to the upper left corner of the image. Dereferencing, also known as geocoding, is the transformation of these relative coordinates into absolute coordinates such as 
latitude and longitude. The first step to the production of the map is the merging of the images. The merging of the images can be decomposed into two parts: stenciling and mosaicking. When the border of the two parts of the image is linear, mosaicking merges them into a single database. However, when the border between these two images is more complex, the boundary is defined by hand, and this is stenciling.

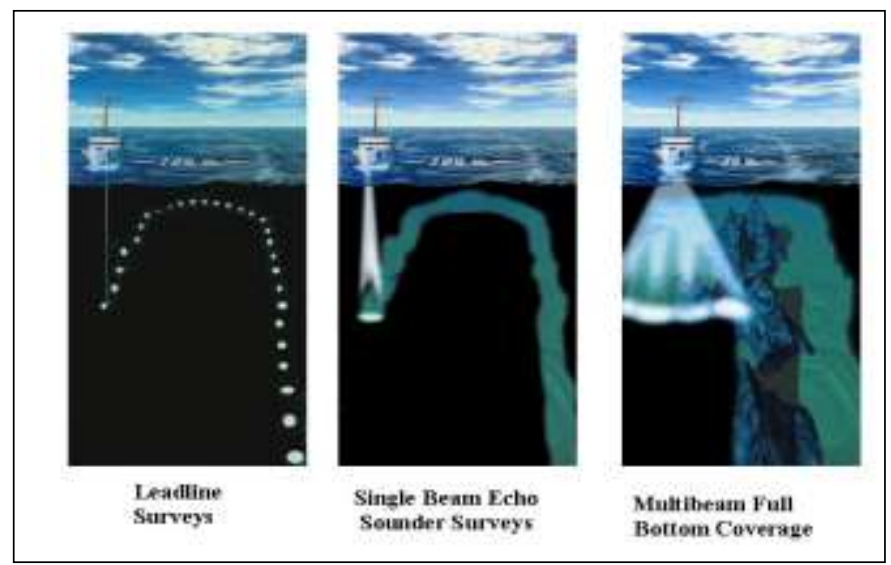

Figure $3.20^{\text {th }}$ century to the present: echo sounders, nauticalcharts.noaa.gov

\section{GEOGRAPHIC INFORMATION SYSTEMS (GIS)}

A new technology that has quickly made a name for itself in ecosystem studies is Geographic Information System (GIS), which helps us collect data of bio geophysical and socioeconomic data in regard to a region [24]. An important role of GIS is that not only helps us collect information, but also processes and visualizes data. In many ways, GIS has the same role as Gen-bank in molecular biology, none other than a big repository of information. By using GIS, we can organize and integrate the relevant information and then by adopting a tool called SITES we generate the options for the reserve network [25]. Using the data collected, the computer creates a network, where the reserves are placed randomly and improve it stage by stage, while adding the new information that is continuously gathered. A disadvantage of GIS is that in order for it to work it requires a graphical user interface (GUI) and minimum skills in Python programming language. ArcGIS (Roberts et al. 2005) is an ongoing survey, almost 40,000 GIS professionals found that ArcGIS is the dominant GIS platform, with more than $78 \%$ of respondents reporting that they used GIS.

\section{TRACKING MOVEMENT}

Monitoring the oceans does not simply involve observing the waves, the circulation of the water, but also monitoring and tracking the oceans life, be it flora or fauna. Until 30 years ago, the tracking of marine species was by tying balloon to the animals, and visually following them [26]. In the 1970s, there were used for the first time very-high-frequency radio technology to track animals, to continue in the 1980s with satellite tracking, using the Argos system. The problem with this method was that for animals which surface only briefly, the time needed to generate the GPS location was not sufficient. To eliminate this problem, there were used two methods, TrackTag and Fastloc. Both these technologies allowed for rapid acquisition of GPS position, allowing also the ability to store the data collected in order to use it at a later date, for comparisons as well as to calculate the animal's movements. A breakthrough was the invention of daily tags, which offered sensor readings and also had triaxle accelerometer [27]. The computerized tags that can archive data such as location, physical setting and also physiological state of the tagged individuals, transmitting this information back to shore are important technologies that have helped us better understand the movement of large swimmers [28, 29].

The use of satellite tracking for seals and cetaceans began in the 1980s but has undergone rapid growth in recent years [30]. Descriptions of migration routes and other habitats have offered novel insights into the basic life patterns of some species, highlighted focal areas for conservation and reinforced multi-national nature [30]. The small, low wattage PTTs attached to the animal are controlled by a microprocessor which is programmed by a computer before it is attached. The microprocessor has been designed to transmit information to the satellites. Polar orbiting satellites are currently used for tracking animals. The satellites are operated by the U.S. National Oceanic and Atmospheric Organization (NOAA) and the same satellites are used to monitor global weather patterns. Attached to these satellites are special instruments operated by a French company, ARGOS CLS. These special instruments are designed to listen to transmitters like those we place on turtles to determine where those transmitters are located. While such a task would seem simple, it is not. Every satellite circles the Earth every 101 minutes; therefore it is only over one place on the planet for about 10 minutes. This means that the satellites make about 6-8 passes per day for 10 minutes each. Using computer mapping programs, or when the location of the data is used, it displays the route they have traveled, and how fast they are swimming. A researcher can also determine the habitat characteristics of the turf's location. The data received from the transmitter in the form of digital codes, which must be deciphered. The codes allow researchers to determine, with varying degrees of reliability, the latitude and longitude of the turtle, the number of dives taken during the last 24 hours, the duration of the most recent dives, and the water temperatures.

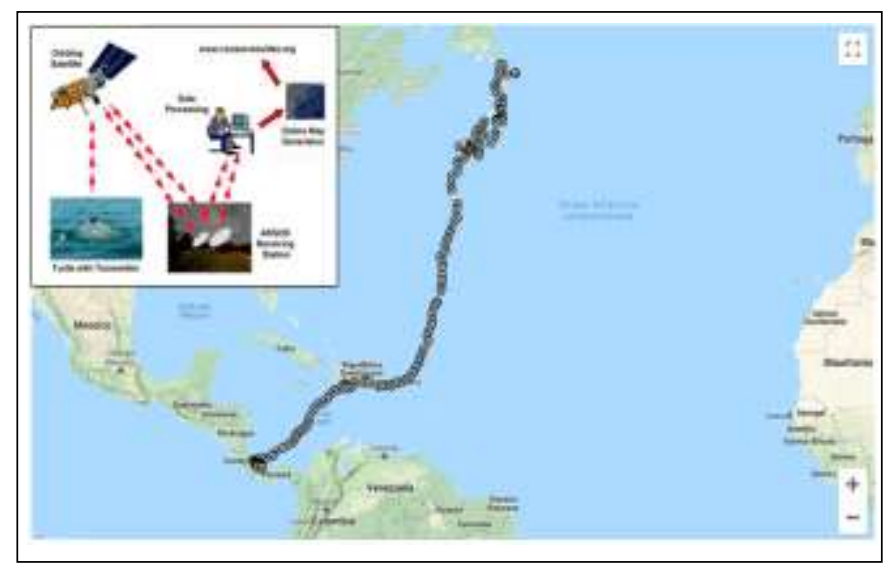

Figure 4. Sea Turtle Tracking,conserveturtles.org/sea-turtle-tracking-works 
Given its global coverage, satellite tracking allows us to follow turtles in near real time and find out what routes they take, no matter how they go, Fig. 3. Intrinsically, satellite tracking is exciting and the arguments for potential research on the subject of public relations and education can also be substantial. The technology has improved and is now available to all workers with online computer access sufficient fiscal resources to buy transmitters, limited consumables and satellite time.

\section{PHOTOGRAMMETRY AND DIGITAL IMAGE PROCESSING DATA}

In recent years, photogrammetry has extended from aerial to terrestrial, and now it's expanded underwater. Using photogramme to try underwater is still in an exploratory phase, but the need for accurate, up to date underwater maps and models already exists for certain industries, such as environmental monitoring, archaeology, forensics, and infrastructure inspection.

With a measurable 3D model or 2D map of a large area, ship or plane wrecks can be documented for scene reconstruction; bridge piers can be inspected for maintenance and repair; ancient cultural artifacts can be mapped and archived for further research; regions can be repetitively monitored for detecting environmental change and more. Photogrammetry has proved to be a very useful resource for zoologists, especially in deep marine environments, Fig 4 . The use of high-quality cameras allows researchers to study the environment much more calmly, and much longer than they have available during a scuba dive. This method has found an application in the study of marine archeology, of fish fauna and also in the study of coral reefs $[31,32,33]$.

\section{GENOMICS AND DNA TRACKING}

Genomics is the study of organisms and their entire genomes, which help scientists to gain understanding about the physiological condition and health of the individuals [34, 35]. The main part of this field is to generate the DNA sequence for all the genes of particular species. A restriction of this technology is the limited application of the genetic resources and online libraries in the modeling of organisms

In the last decade an important role in the development of this technology has had the Evolutionary Genomics group at the Joint Genome Institute (www.jgi.doe.gov/whoweare/ evogen) that has done the sequencing of coral genome, the sequencing of the salmon [36], purple sea urchins [37]. Recent trends in molecular genetics and population genetics, give us new tools in order to measure the dispersal of the populations, to examine gene flow over evolutionary time frames, with the results that species with a high potential for dispersal tended to have only slight genetic variation from place to place [38].

The problem with using this method is in the cases when the population does not migrate. In order to help pass this problem, we can carefully measure the build-up of the genetic differences over distance, and then compare these results to the simulation ones in virtual populations that have defines dispersal parameters [39].

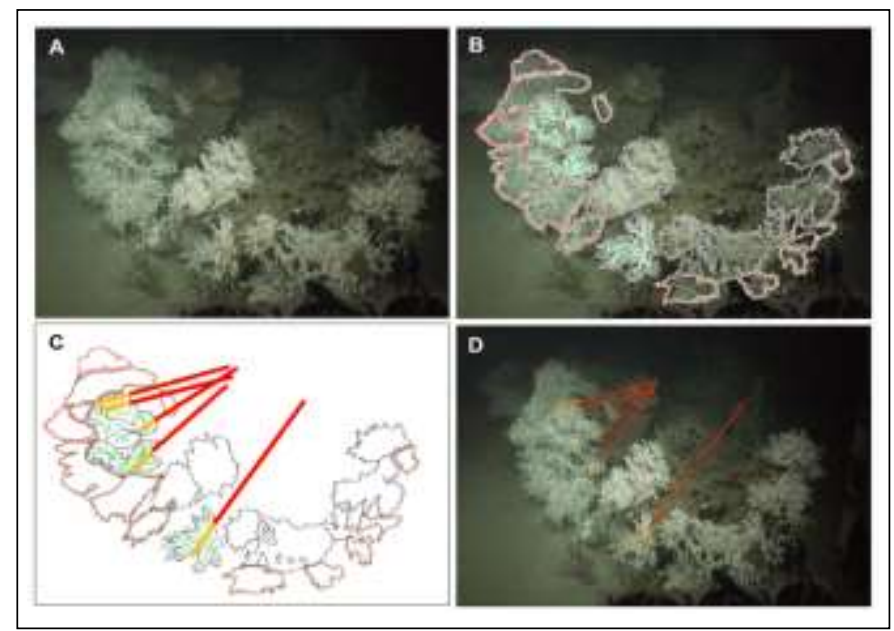

Figure 5. Method applied to measure living and dead layers of a colony of Lopheliapertusa coral with the method of Photogrammetry

\section{ECOLOGICAL SIMULATORS}

According to $\lceil 40\rceil$ an ecosystem model is an abstract, usually mathematical, representation of an ecological system (ranging in scale from an individual population, to an ecological community, or even an entire biome), which is studied to better understand the real system. But it took years for the theory to develop into the creation of an ecological simulator based on a series of mathematical algorithms. Over the past fifteen years, a series of ecological simulators have been created, some of which are accessible online for free. An ecological simulator consists of sets of routines which are called menu-driven program to perform tasks such as automatic compiling, linking and loading of a model, simulation runs, graphical and numerical output, analysis of results and comparison with available field data. It provides a choice of integration methods for simulating continuous processes and can also handle discrete processes such as encountered in systems with age-or-size-structured populations.

\section{CONCLUSIONS}

The instruments described and adopted in various researches in the field of Marine biology and geology have been and continue to be effective. They contribute relevant information on the health of resident organisms and abundance data on the diversity of them. Tools like these can help establish standards as well as clear and precise protocols on what to do in some circumstances. Furthermore, the ecological simulators can build very accurately the future scenarios of the development of an ecosystem, giving us the possibility to predict what will happen with climate change that we are experiencing such as global warming, ocean acidification and the extinction of many species of our marine fauna.

However precise they may be, these tools cannot replace the work of marine biologists, geologists and archaeologists. They can only help research by shortening the time and 
sometimes reducing the costs and risk of researchers. Without doubt the mechanisms of development of an ecosystem are variable given that its components are living organisms, for which the experience of a human entity is needed to understand the evolution of an ecosystem.

\section{REFERENCES}

[1] Bondur V. Aerospace methods in Modern Oceanology. In: "New Ideas in Oceanology". Vol. 1: Physics. Chemistry. Biology. // Ed. by M.E. Vinogradov, S.S. Lappo, - M.:Nauka, 2004, p.p. 55 - 117 (In Russian).

[2] Bondur, V. G. (2005, June). Complex satellite monitoring of coastal water areas. In Proc. of (Vol. 31, pp. 1-6).

[3] Palumbi, Stephen R., Steven D. Gaines, Heather Leslie, and Robert R. Warner. "New wave: high-tech tools to help marine reserve research."Frontiers in Ecology and the Environment1, no. 2 (2003): 7379.

[4] Wang LW, Sousa P, Gong P, Biging GS. 2004. Comparison of IKONOS and QuickBird images for mapping mangrove species on the Caribbean coast of Panama. Remote Sensing of Environment 91: 432-440

[5] Godley, B. J., Blumenthal, J. M., Broderick, A. C., Coyne, M. S., Godfrey, M. H., Hawkes, L. A., \& Witt, M. J. (2008). Satellite tracking of sea turtles: where have we been and where do we go next? Endangered Species Research, 4(1-2), 3-22

[6] Palumbi SR. 2003. Population genetics, demographic connectivity and the design of marine reserves. EcolAppl 13: S146-58.

[7] James M, Armsworth P, Mason L, and Bode L. 2002. The structure of reef fish metapopulations: modelling larval dispersal and retention patterns. Proc Roy SocLond B Bio 269: 2079-86.

[8] Winant CD. 1996. Surface circulation in the Santa Barbara Channel. Oceanography 9: 114-21.

[9] Harms, S., \& Winant, C. D. (1998). Characteristic patterns of the circulation in the Santa Barbara Channel. Journal of Geophysical Research: Oceans, 103(C2), 3041-3065.

[10] Gower, J., King, S., \&Goncalves, P. (2008). Global monitoring of plankton blooms using MERIS MCI. International Journal of Remote Sensing, 29(21), 6209-6216

[11] Kostianoy, A. G., Lavrova, O. Y., Mityagina, M. I., Solovyov, D. M., \&Lebedev, S. A. (2013). Satellite monitoring of oil pollution in the Southeastern Baltic Sea. In Oil pollution in the Baltic Sea(pp. 125-153). Springer, Berlin, Heidelberg

[12] Shuchman, R., Korosov, A., Hatt, C., Pozdnyakov, D., Means, J., \& Meadows, G. (2006). Verification and application of a bio-optical algorithm for Lake Michigan using SeaWiFS: a 7-year inter-annual analysis. Journal of Great Lakes Research, 32(2), 258-279

[13] Forzieri, G., Degetto, M., Righetti, M., Castelli, F., \&Preti, F. (2011). Satellite multispectral data for improved floodplain roughness modelling. Journal of hydrology, 407(1-4), 41-57.

[14] Shcherbak, S. S., Lavrova, O. Y., Mityagina, M. I., Bocharova, T. Y., Krovotyntsev, V. A., \&Ostrovskii, A. G. (2008). Multisensor satellite monitoring of seawater state and oil pollution in the northeastern coastal zone of the Black Sea. International Journal of Remote Sensing, 29(21), 6331-6345

[15] Gentemann, C. L., Donlon, C. J., Stuart-Menteth, A., \& Wentz, F. J. (2003). Diurnal signals in satellite sea surface temperature measurements. Geophysical Research Letters, 30(3).

[16] Pattiaratchi, C., Lavery, P., Wyllie, A., \& Hick, P. (1994). Estimates of water quality in coastal waters using multi-date Landsat Thematic Mapper data. International Journal of Remote Sensing, 15(8), 1571-1584

[17] Graziani, S., Beaubien, S. E., Bigi, S., \& Lombardi, S. (2014). Spatial and temporal pCO2 marine monitoring near Panarea Island (Italy) using multiple low-cost GasPro sensors. Environmental science \& technology, 48(20), 12126-12133.

[18] Wencel, D., Abel, T., \&McDonagh, C. (2013). Optical chemical pH sensors. Analytical chemistry, 86(1), 15-29
[19] Murali, R. M., Shrivastava, D., \&Vethamony, P. (2009). Monitoring shoreline environment of Paradip, east coast of India using remote sensing. Current science, 79-84

[20] Lee, Z., Marra, J., Perry, M. J., \&Kahru, M. (2015). Estimating oceanic primary productivity from ocean color remote sensing: A strategic assessment. Journal of Marine Systems, 149, 50-59.

[21] Kenny, A. J., Cato, I., Desprez, M., Fader, G., Schüttenhelm, R. T. E., \& Side, J. (2003). An overview of seabed-mapping technologies in the context of marine habitat classification. ICES Journal of Marine Science, 60(2), 411-418.

[22] South, H. M., Cronin, D. C., Gordon, S. L., \&Magnani, T. P. (1998) Technologies for sonar processing. Johns Hopkins APL technical digest, 19(4), 459-469.

[23] Blondel, P., \&Sichi, O. G. (2009). Textural analyses of multibeam sonar imagery from Stanton Banks, Northern Ireland continental shelf Applied Acoustics, 70(10), 1288-1297

[24] Wright D (Ed). 2002. Undersea with GIS. Redlands, CA: ESRI Pres

[25] Airame S, Dugan JE, Lafferty KD, et al. 2003. Applying ecological criteria to marine reserve design: a case study from the California Channel Islands. EcolAppl 13: S170-84

[26] Hays, S. (1998). The cultural contradictions of motherhood. Yale University Press.

[27] Wilson, R. P., Shepard, E. L. C. \&Liebsch, N. 2008 Prying into the intimate details of animal lives: use of a daily diary on animals. Endang. Species Res. 4, 123-137. (doi:10.3354/esr00064)

[28] Block BA, Teo SLH, Walli A, Boustany A, Stokesbury MJW, Farwell CJ, Weng KC, Dewar H, Williams TD. 2005. Electronic tagging and population structure of Atlantic bluefin tuna. Nature 434: 1121-1127.

[29] Boustany AM, Davis SF, Pyle P, Anderson SD, Le Boeuf BJ, Block BA. 2002. Satellite tagging: Expanded niche for white sharks. Nature 415: $35-36$.

[30] Godley, B. J., Blumenthal, J. M., Broderick, A. C., Coyne, M. S., Godfrey, M. H., Hawkes, L. A., \& Witt, M. J. (2008). Satellite tracking of sea turtles: where have we been and where do we go next? Endangered Species Research, 4(1-2), 3-22

[31] Drap, P., Seinturier, J., Hijazi, B., Merad, D., Boi, J. M., Chemisky, B., ...\& Long, L. (2015). The ROV 3D Project: Deep-sea underwater survey using photogrammetry: Applications for underwater archaeology. Journal on Computing and Cultural Heritage (JOCCH), 8(4), 21.

[32] Leatherdale, J. D., \& Turner, D. J. (1983). Underwater photogrammetry in the North Sea. The Photogrammetric Record, 11(62), 151-167.

[33] Li, R., Tao, C., Zou, W., Smith, R. G., \& Curran, T. A. (1996). An underwater digital photogrammetric system for fishery geomatics. International Archives of Photogrammetry and Remote Sensing, 31, 319-323.

[34] Hofmann GE, Burnaford JL, Fielman KT. 2005. Genomics-fueled approaches to current challenges in marine ecology. Trends in Ecology and Evolution 20: 305-311.

[35] Thomas MA, Klaper R. 2004. Genomics for the ecological toolbox. Trends in Ecology and Evolution 19: 439-445.

[36] von Schalburg K, Rise M, Cooper G, Brown G, Gibbs AR, Nelson C, Davidson W, Koop B. 2005. Fish and chips: Various methodologies demonstrate utility of a 16,006-gene salmonid microarray. BMC Genomics 6: 126

[37] https://www.hgsc.bcm.edu/other-invertebrates/sea-urchin-genomeproject.

[38] Hellberg, M. E., Burton, R. S., Neigel, J. E., \& Palumbi, S. R. (2002). Genetic assessment of connectivity among marine populations. Bulletin of marine science, 70(1), 273-290.

[39] Palumbi SR. 2003. Population genetics, demographic connectivity and the design of marine reserves. EcolAppl 13: S146-58.

[40] Hall, C. A., \& Day Jr, J. W. (1977). Ecosystem modeling in theory and practice: an introduction with case histories. 